\title{
KARAKTERISASI BATUAN SERPIH PADA LAPANGAN "RK" FORMASI TANJUNG, CEKUNGAN BARITO, KALIMANTAN SELATAN SEBAGAI POTENSI SHALE HYDROCARBON
}

\author{
Taufan Amersia Sumotarto ${ }^{1, \text { a) }}$ Abdul Haris ${ }^{1}$, Dr. Andang Bachtiar ${ }^{2}$, Alfian \\ Usman $^{3}$ \\ ${ }^{1}$ Universitas Indonesia \\ ${ }^{2}$ Dewan Energi Nasional \\ ${ }^{3}$ PT. Pertamina (Persero) \\ Email: a)tamersia22@gmail.com
}

\begin{abstract}
Abstrak
Eksplorasi dan eksploitasi di Indonesia saat ini masih terfokus pada energi konvensional hidrokarbon dibandingkan energi nonkonvensional hidrokarbon seperti gas serpih. Gas serpih adalah salah satu energi nonkonvensional yang kaya material organic dan mencapai kematangan, pada kondisi dan tipe tertentu mampu berfungsi sebagai reservoir minyak dan gas. Formasi Tanjung adalah batuan induk dari Cekungan Barito, terletak diKalimantan Selatan, berpotensi sebagai Shale Hydrocarbon. Pada penelitian ini dilakukan integrasi dari tiga metode diantaranya menggunakan analisis geokimia organik, petrofisika dan interpretasi seismik yang menjadi dasar untuk melihat hubungan kekayaan material organik dan kematangan material organik pada potensi gas serpih di wilayah tersebut. Tahap pertama adalah analisis geokimia organik pada Formasi Tanjung didapat tingkat kekayaan materi organik berkisar $1.26-5.98$ wt\% (Baik - sangat baik), jendela awal kematangan pada kedalaman $2170 \mathrm{~m}$ dan kategori tipe kerogen II/III menghasilkan minyak dan gas. Tahap kedua adalah analisis petrofisika yang meliputi perhitungan TOC secara kontinyu, hasil dari analisis petrofisika ini divalidasi dengan nilai analisis laboratorium, didapat nilai regresi 0.923 . Tahap selanjutnya adalah melakukan interpretasi seismik dengan metode inversi impedansi akustik untuk melihat persebaran batuan serpih dengan nilai $17718-28222 \mathrm{ft} / \mathrm{s} * \mathrm{~g} / \mathrm{cc}$, arah penyebaran batuan serpih sebagai potensi shale hydrocarbon berada di timur dan tenggara daerah penelitian.
\end{abstract}

Kata-kata kunci: Shale Hydrocarbon, Formasi Tanjung, Material Organik, Petrofisika dan Inversi Impedansi Akustik

\begin{abstract}
Exploration and exploitation in Indonesia currently still focused on conventional hydrocarbon energy than the energy of the nonkonvensional hydrocarbons such as shale gas. Shale gas is one of the energyrich organic material nonkonvensional and reach maturity, on the conditions and certain types are capable of functioning as a reservoir of oil and gas. The formation of the Cape is the parent rock of the Barito Basin, located diKalimantan South, potentially as Shale Hydrocarbon. This research was conducted on the integration of the three methods include using organic geochemical analysis, seismic interpretation and petrofisika which became the basis for the wealth of organic material see the relationship and maturity of organic material on the potential of shale gas in the region. The first phase is the analysis of Organic Geochemistry in Formation of Cape obtained the level of wealth of organic
\end{abstract}


matter ranged from $1.26-5.98 \mathrm{wt} \%$ (Good-excellent), the initial maturity of the window at a depth of $2170 \mathrm{~m}$ and category II/III kerogen type produces oil and gas. The second phase is the analysis of petrofisika which include calculation of TOC continuously, the results of the analysis of this petrofisika validated with the value of the laboratory analysis, the regression value obtainable 0923 . The next step is doing seismic interpretation with acoustic impedance inversion method to see the spread of the shale rocks with a value of $17718-28222 \mathrm{ft} / \mathrm{s} * \mathrm{~g} / \mathrm{cc}$, the direction of spread of shale rocks as shale hydrocarbon potential in the East and Southeast areas of research.

Keywords: Shale Hydrocarbon Formation, Cape, organic Material, Petrofisika and Acoustic Impedance Inversion

\section{PENDAHULUAN}

Dengan berjalannya waktukebutuhan minyak dan gas bumi semakin bertambah, akan tetapi jumlah cadangan akan keberadaan bahan bakar fosil semakin berkurang. Eksplorasi dan eksploitasi di Indonesia saat ini masih terfokus pada energi konvensional hidrokarbon dibandingkan energi nonkonvensional hidrokarbon seperti gas serpih.Gas serpih adalah salah satu energi nonkonvensional yang kaya material organik dan mencapai kematangan, selain berfungsi sebagai batuan induk, pada kondisi dan tipe tertentu mampu berfungsi sebagai reservoir minyak dan gas.Permeabilitas dan porositas primer pada serpih umumnya sangat kecil sehingga sering dianggap sebagai batuan penyekat dalam sistem perminyakan (petroleum system). Namun perlu dicatat bahwa serpih dapat menyimpan hidrokarbon dalam jumlah besar sehingga menambah tingkat keyakinan dan kepastian bawah permukaan.Wilayah Cekungan Barito pada Formasi Tanjung, memiliki potensi cadangan gas serpih sebesar 56.61 TCF (Pertamina, 2013).Amerika Serikat yang telah memulai eksplorasi dan eksploitasi energi gas serpih, dimana lingkungan pengendapannya marine dengan umur Mesozoic, sedangkan karakteristik serpih di Cekungan Barito khususnya dan di Indonesia pada umumnya memiliki lingkungan pengendapan lakustrin dengan umur Tersier. Penulis mencoba untuk mengintegrasikan tiga metode di antaranya menggunakan analisis geokimia organik, petrofisik dan interpretasi seismik yang menjadi dasar untuk melihat hubungan Kekayaan Material Organik, Kematangan Material Organik, dan Penyebaran pada potensi gas serpih di wilayah tersebut dimana telah memasuki zona matang (Mature).Diharapkan penelitian ini dapat memberikan pemahaman dan informasi dalam menentukan apakah batuan serpih yang berada di wilayah penelitian memiliki potensi sumber daya gas yang cukup untuk dilakukan eksplorasi atau tidak dan aplikasinya dalam pengembangan lapangan yang ada di daerah penelitian.

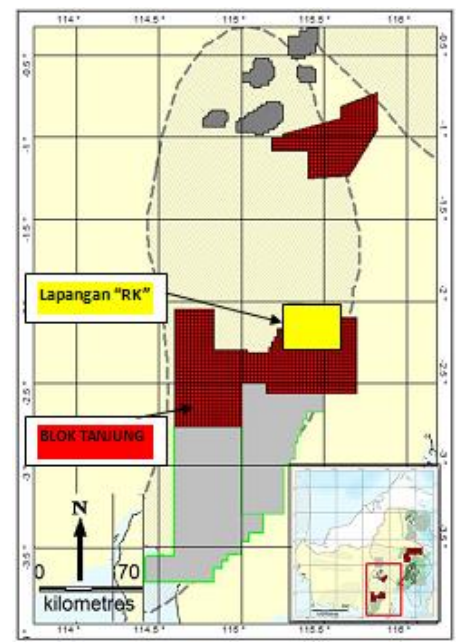

GAMBAR 1. Lokasi penelitian (kotak kuning) terletak di daerah Tanjung Raya, Kalimantan Selatan, Indonesia 


\section{METODE PENELITIAN}

\subsection{Analisis Geokimia}

Dalam menganalisis geokimia batuan induk, dalam hal ini batuan serpih diperlukan beberapa analisis yang menyangkut kuantitas, kualitas, dan kematangan material organik.Pada prinsipnya, jumlah hidrokarbon yang dihasilkan berhubungan dengan kandungan material organik dalam batuan induk. Oleh karena itu, faktor kuantitas material organik sering disebut dengan karbon organik total (TOC). Sampel batuan dengan kandungan TOC rendah biasanya dianggap tidak mampu membentuk hidrokarbon yang komersial. Titik batas diskualifikasi untuk batuan induk berpotensi sekitar $0.5 \%$ untuk batuan induk berupa serpih (batuan non-karbonat) dan $0.3 \%$ untuk batuan karbonat (Tissot dan Welte, 1984).

Analisis Rock-Eval Pyrolisis merupakan metode pendekatan langsung terhadap kualitas dan tipe hidrokarbon yang dilakukan dengan membakar sejumlah kecil contoh batuan tanpa melibatkan unsur oksigen pada temperatur tinggi untuk lebih mendekati peristiwa pembentukan hidrokarbon yang sesungguhnya terjadi di alam.

Penentuan kematangan material organik menggunakan analisis vitrinit.Pengukuran Ro dilakukan secara statistik. Oleh karena itu, jumlah pengukuran diusahakan berkisar antara 10-100 bacaan, setelah pengukuran mencapai jumlah maksimal, nilai - nilai bacaan tersebut diplotkan dalam suatu kurva histogram dan profil kematangan dari data Ro dan kedalaman.

\subsection{Analisis Petrofisika}

Analisa petrofisik merupakan proses yang bertujuan untuk menganalisa sifat-sifat fisik batuan berdasarkan data log. Data log yang tersedia umumnya data Gamma ray, Resistivitas, Neutron, densitas dan Sonic. Dari sifat-sifat fisik tersebut dapat membantu dalam menganalisa formasi batuan.

Nilai TOC yang diperoleh dari rock-eval memiliki keterbatasan karena tidak kontinyu atau hanya pada kedalaman-kedalaman tertentu. Oleh karena itu agar TOC di semua interval kedalaman dapat diketahui maka dilakukan perhitungan pada sumur dengan metode Multi linier regresi menurut Verma dan Marfurt., (2014) melalui log Gamma Ray, $\log$ Density, $\log$ Neutron-Porosity, $\log P$-wave dan $\log$ resistivity. Metode multi linier regresi dapat memberikan hasil yang lebih baik untuk perhitungan TOC kontinyu.

\subsection{Analisis Geofisika}

Tujuan yang paling penting dalam interpretasi seismik adalah mengolah data seismik menjadi informasi geologi sebanyak mungkin dalam bentuk-bentuk struktur bawah permukaan serta horizon yang menjadi target dalam penelitian ini. Dalam analisis geofisika, data yang digunakan berupa data seismik dan data sumur di wilayah yang akan diteliti. Inversi Impedansi Akustik bertujuan untuk melihat persebaran litologi pada nilai low frequency data seismik, karena nantinya dari inversi akan mengisi data low frequency dari sesimik. Tetapi sebelumnya dilakukan uji sensitivitas dari nilai impedansi akustik terhadap nilai pemodelan TOC yang berfungsi sebagai input untuk penyebaran batuan serpih yang mengandung nilai TOC sebagai potensi gas serpih. 


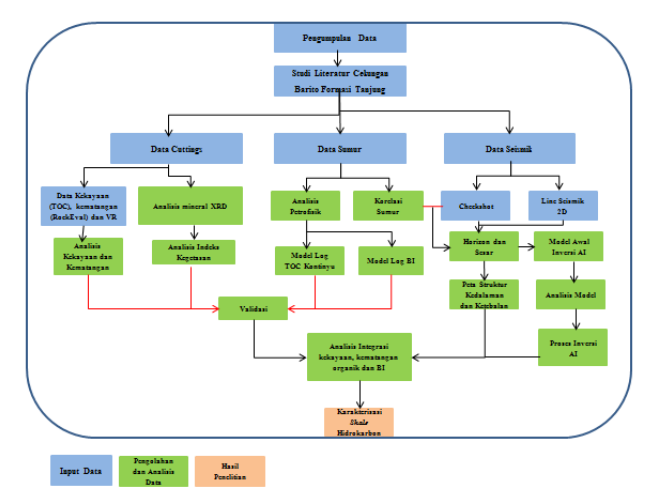

GAMBAR 2.1. Metode pengerjaan pengolahan data

Tabel 2.1. Parameter potensi batuan induk (Peter dan Cassa, 1994).

\begin{tabular}{ccccc}
\hline Kualitas & TOC & \multicolumn{3}{c}{ Rock-Eval Pyrolisis } \\
\cline { 3 - 5 } & $($ wt \% $)$ & $\begin{array}{c}\mathrm{S} 1 \\
(\mathrm{mg} \mathrm{HC} / \mathrm{g})\end{array}$ & $\begin{array}{c}\mathrm{S} 2 \\
(\mathrm{mg} \mathrm{HC} / \mathrm{g})\end{array}$ & $\begin{array}{c}\mathrm{S} 1+\mathrm{S} 2 \\
(\mathrm{mg} \mathrm{HC} / \mathrm{g})\end{array}$ \\
\hline Buruk & $<0,5$ & $0-0,5$ & $<2,5$ & $<2$ \\
Sedang & $0,5-1$ & $0,5-1$ & $2,5-5$ & $2-5$ \\
Bagus & $1-2$ & $1-2$ & $5-10$ & $5-10$ \\
Sangat & $2-4$ & $2-4$ & $10-20$ & $10-20$ \\
Bagus & & & & $>20$ \\
Excellent & $>4$ & $>4$ & $>20$ &
\end{tabular}

Tabel 2.2 Tipe kerogen dan kecenderungan jenis hidrokarbon yang akan dihasilkan (Peters dan Cassa, 1994)

\begin{tabular}{cccc}
\hline Tipe Kerogen & $\begin{array}{c}\text { Hidrogen Indeks } \\
(\mathbf{m g} \text { HC/g TOC) }\end{array}$ & $\mathbf{S}_{2} / \mathbf{S}_{3}$ & $\begin{array}{c}\text { Jenis Hidrokarbon } \\
\text { yang dihasilkan }\end{array}$ \\
\hline I & $>600$ & $>15$ & Minyak \\
II & $300-600$ & $10-15$ & $\begin{array}{c}\text { Minyak } \\
\text { Campuran minyak } \\
\text { dan gas }\end{array}$ \\
II/III & $200-300$ & $5-10$ & Gas \\
III & $50-200$ & $1-5$ & $\begin{array}{c}\text { Tidak ada } \\
\text { IV }\end{array}$ \\
\end{tabular}

\section{HASIL DAN PEMBAHASAN}

\subsection{Karakteristik Geokimia Serpih}

Analisis gas serpih dilakukan pada sumur, yaitu: Bkg-2 dengan menggunakan data cutting pada lapangan "RK", Formasi Tanjung, Cekungan Barito. Analisis yang dilakukan terhadap batuan serpih pada sumur Bkg-2 meliputi potensi hidrokarbon (\%TOC), kualitas material organik (rock-eval pyrolisis) dan kematangan gas serpih (vitrinite reflectance).

Berdasarkan analisis kandungan material dan evaluasi pirolisis batuan yang dilakukan pada interval kedalaman 2170 - 2948 meter, dapat diketahui bahwa potensi hidrokarbon yang terdapat pada sumur Bkg-2 ini memiliki tingkat kandungan material organik dengan klasifikasi tinggi yaitu Good-Excellent (parameter menurut Peter dan Cassa, 1994) yang berkisar antara $1.26-5.98$ wt\% (Tabel 3.1). Dari nilai HI $111-268 \mathrm{mgHC} / \mathrm{g}$ TOC dapat diasumsikan bahwa Formasi Tanjung pada sumur Bkg-2 ini cenderung akan menghasilkan oil-gas(Gambar 3.1).

Untuk mengetahuitingkat kematangan material organik pada sumur Bkg-2 ini, analisis data reflektansi vitrinit dilakukan pada 9 sampel batuan, dan dapat dikategorikan bahwa Formasi Tanjung pada sumur ini merupakan batuan serpih yang matang (mature) dengan nilai reflektansi vitrinit antara 
0.52 - 0.63.Berdasarkan data burial historysumur Bkg-2 present gas window hadir pada kedalaman 2681 meter di Formasi Tanjung Bagian Bawah pada 20 Ma (Gambar 3.2).

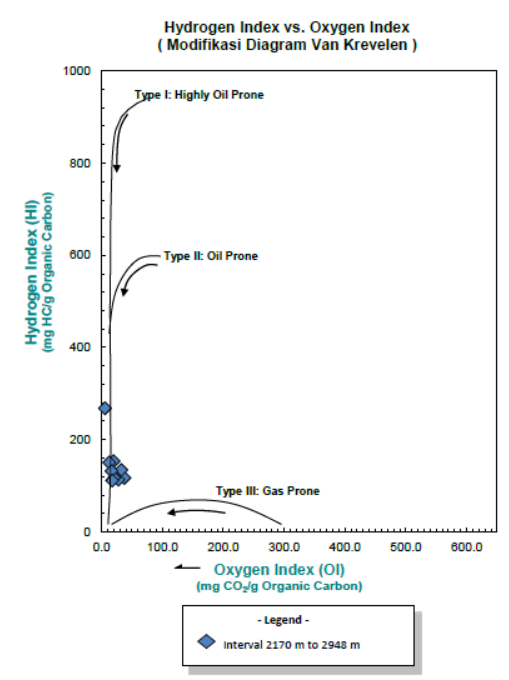

GAMBAR 3.1. Perbandingan antara HI dengan OI modifikasi diagram Van Krevelen pada sumur Bkg-2 (Peters dan Cassa, 1994).

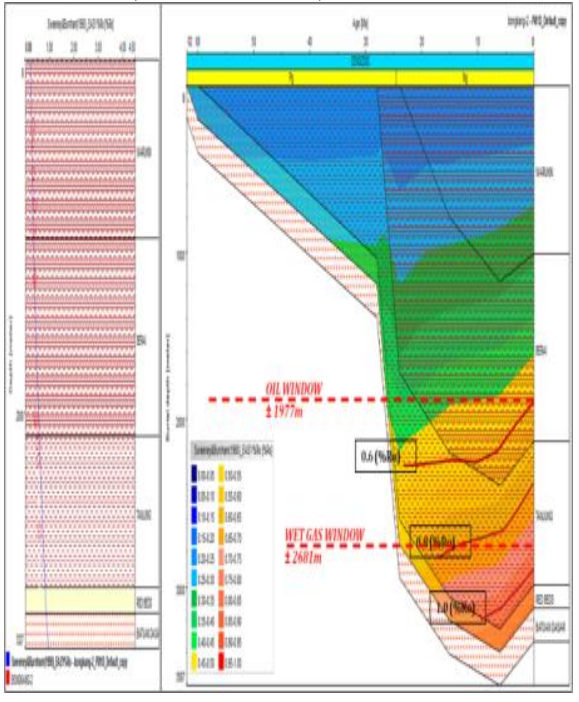

GAMBAR 3.2. Pemodelan tingkat kematangan pada sumur Bkg-2

Tabel 3.1 Data TOC, Hydrogen Index (HI) dan Oxygen Index (OI) pada sumur Bkg-2

\begin{tabular}{cccrcc}
\hline No. & Depth (m) & Sample & \multicolumn{1}{c}{ TOC } & HI & OI \\
\cline { 3 - 4 } & & & 1,36 & 117 & 38 \\
\hline 1 & 2170 & Cuttings & 1,26 & 134 & 33 \\
2 & 2270 & Cuttings & 1,51 & 113 & 28 \\
3 & 2370 & Cuttings & 1,85 & 154 & 20 \\
4 & 2470 & Cuttings & 1,32 & 117 & 21 \\
5 & 2570 & Cuttings & 1,43 & 150 & 13 \\
6 & 2670 & Cuttings & 2,62 & 132 & 16 \\
7 & 2770 & Cuttings & 5,98 & 268 & 6 \\
8 & 2870 & Cuttings & 4,39 & 111 & 18 \\
9 & 2948 & Cuttings & & &
\end{tabular}

\subsection{Perhitungan TOC Multi Linier Regresi}

Selanjutnya dilakukan analisis petrofisika dengan data geokimia laboratorium yang dijadikan sebagai data validasi atau pemandu dalam penelitian ini. Sumur yang dipakai dalam analisis ini hanya sumur Bkg-2 dikarenakan Formasi Tanjung pada sumur ini mencapai tingkat kematangan dari nilai reflektansi vitrinit yang dijadikan sebagai zona matang.Pada analisis petrofisika dengan menggunakan metode multi linier regresi menurut Verma dan Marfurt., (2014), yaitu melakukan perhitungan terhadap hubungan dari TOC hasil analisis laboratorium dengan seluruh parameter log yang ada pada sumur Bkg-2. Data log yang digunakan antara lain log Gamma Ray, log Density, log Neutron-Porosity, $\log P$-wavedan $\log$ resistivity. Tahap awal sebelum melakukan analisis adalah melihat nilai regresi dari nilai TOC dengan parameter log.Menggunakan jumlah sampel yang sama parameter TOC, log Gamma Ray, log Density, log Neutron-Porosity dan log P-Wave dimasukkan ke dalam perhitungan multi linier regresi untuk menghasilkan TOC Model dari perhitungan multi linier regresi.

Berikut adalah persamaan multi linier regresi yang digunakan mencari konstanta untuk mendapatkan nilai pemodelan TOC:

$$
y=(b o)+(b 1 * x 1)+(b 2 * x 2)+(b 3 * x 3)+(b 4 * x 4)
$$

Dari persamaan di atas untuk mencari nilai kontstanta $b$, dilakukan penganalogian dengan TOC sebagai $\mathrm{y}$, data $\log$ gamma ray sebagai $\mathrm{x} 1$, data $\log$ density sebagai $\mathrm{x} 2$, data $\log$ neutron sebagai $\mathrm{x} 3$, dan data $\log p$-wave sebagai $\mathrm{x} 4$. Di bawah ini adalah hasil perhitungan multi linear regresi dengan MatLab: 


$$
\begin{gathered}
\text { TOC }=2.1009+(-0.0596 * \text { Gamma_Ray })+(1.0733 * \text { Density })+(3.9816 * \text { Neutron_Porosity })+ \\
\left(0.0042 * P \_w a v e\right)
\end{gathered}
$$

$$
\begin{aligned}
& \text { b0 }(\text { konstanta })=2.1009 \\
& \text { b1 }(\text { konstanta })=-0.0596 ; \text { dan x } 1=\log \text { G-Ray }(\text { api }) \\
& \text { b2 }(\text { konstanta })=1.0733 ; \text { dan x } 2=\log \text { Density }(\mathrm{g} / \mathrm{cc}) \\
& \text { b3 }(\text { konstanta })=3.9816 ; \text { dan x } 3=\log \text { Neutron }(\mathrm{v} / \mathrm{v}) \\
& \text { b4 }(\text { konstanta })=0.0042 ; \text { dan } \times 4=\log \text { Sonic }(\text { us/ft })
\end{aligned}
$$

Dapat dilihat hasil pemodelan TOC pada sumur Bkg-2 berdasarkan parameter log yang ada yang dikalkulasi dengan multi linier regresi menghasilkan nilai TOC yang baik, hal ini dibuktikan dengan validasi nilai TOC Laboratorium yaitu nilai regresi Pearson mencapai 0.924.

Tabel 3.2 Hasil TOC Model dibandingkan dengan TOC Lab dengan jumlah sampel yang sama pada sumur Bkg-2

\begin{tabular}{ccc}
\hline Depth $(\mathbf{m})$ & TOC Lab & TOC Model \\
\hline 2170 & 1.36 & 1.37 \\
2270 & 1.26 & 1.44 \\
2370 & 1.51 & 1.84 \\
2470 & 1.85 & 2.26 \\
2570 & 1.32 & 1.19 \\
2670 & 1.43 & 1.41 \\
2770 & 2.62 & 2.60
\end{tabular}

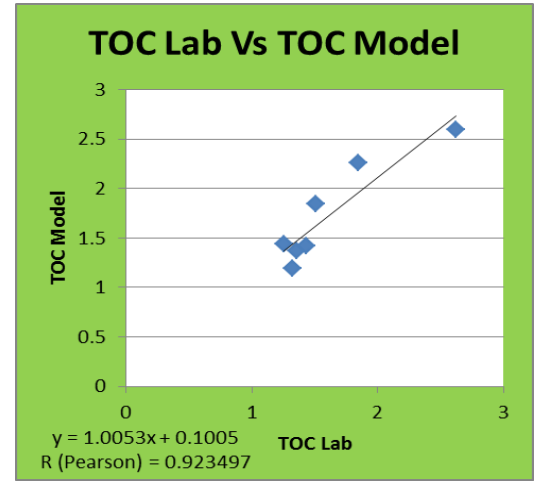

Gambar 3.3 Hasil crossplot TOC Lab dengan TOC Model

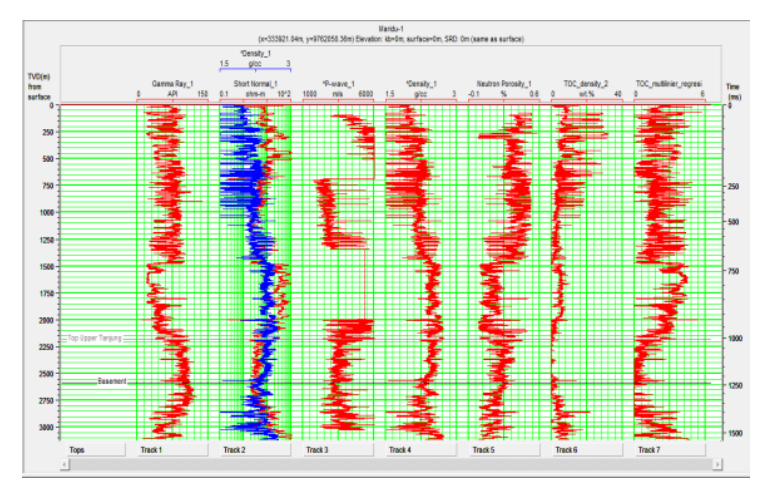

Gambar 3.4 Contoh hasil pemodelan log TOC dengan multi linear regresi

\subsection{Analisis Inversi Impedansi Akustik}

Sebelum melakukan proses inversi terlebih dahulu dilakukan pembuatan suatu model geologi dengan menggunakan data-data yang ada, antara lain data sumur dan data horizon. Model geologi ini disebut juga sebagai model awal (initial model), dimana data model awal ini digunakan setiap melakukan inversi seismik, untuk semua metode inversi seismik. Terdapat beberapa hal yang mempengaruhi kualitas dari model awal dan yang terpenting adalah data sumur yang telah diikatkan dengan data seismik, wavelet, dan data horizon. Data sumur digunakan sebagai acuan nilai impedansi, baik untuk impedansi gelombang-P (Zp) maupun impedansi densitas (Dn), yang dihitung dari nilai log kecepatan gelombang-P (Vp) dan densitas $(\rho)$. Sedangkan data horizon digunakan sebagai panduan dalam melakukan interpolasi nilai impedansi gelombang-P untuk seluruh volum seismik.Hasil dari analisis model inversi pada sumur B-2 menunjukkan hasil yang cukup baik, terlihat adanya kecocokan antara parameter impedansi dari data sumur dengan kurva impedansi 
akustik hasil inversi. Pada sumur B-2 menunjukkan nilai korelasi antara sintetik serta data seismik yaitu 0.991 dengan eror, rms sebesar 2369.46 dan eror sebesar 0.134 (Gambar 3.5).

Untuk mengetahui penyebaran batuan serpih yang berpotensi menghasilkan hidrokarbon adalah melakukan ekstraksi nilai impedansi akustik pada peta struktur kedalaman. Hasil inversi ini juga digunakan untuk melihat penyebaran nilai TOC pada penampang dari hasil inputan crossplot nilai akustik impedansi dengan TOC, dilihat dari persamaan linier dari hubungan keduanya.

Hasil dari nilai crossplot antara parameter P-Impedance dengan TOC model dijadikan acuan dalam menganalisis penyebaran batuan serpih yang berpotensi sebagai hidrokarbon dari data seismik. Dapat dilihat dari hasil penampang inversi impedansi akustik dan TOC pada lintasan seismik 91tr-46 yang dilalui sumur B-2 (Gambar 3.6 dan 3.7). Zona antara formasi Top Lower Tanjung sampai Top Basement yang ditandai dengan kotak warna hitam, diindikasikan memiliki nilai akustik impedansi berkisar antara $17718-28222 \mathrm{ft} / \mathrm{s}^{*} \mathrm{~g} / \mathrm{cc}$, nilai TOC $0.5-1.12 \%$ (cukup-baik).

Gambar 3.8 memperlihatkan hasil analisis penyebaran impedansi akustik pada formasi top lower Tanjung. Diindikasikan memiliki nilai diatas $38000 \mathrm{ft} / \mathrm{s} * \mathrm{~g} / \mathrm{cc}$ dengan warna kuning sampai merah banyak tersebar di sebelah tenggara daerah penelitian. Begitu juga dengan peta persebaran TOC (Gambar 3.9), pada daerah penelitian mengindikasikan persebaran TOC dengan nilai $2-6 \%$ banyak tersebar di sebelah tenggara daerah penelitian, hal ini mengindikasikan bahwa nilai TOC yang tinggi dan matang banyak tersebar di kedalaman yang cukup dalam (>2000 m), sehingga membuktikan bahwa tingkat kematangan berpengaruh terhadap kedalaman pengendapan batuan serpih.

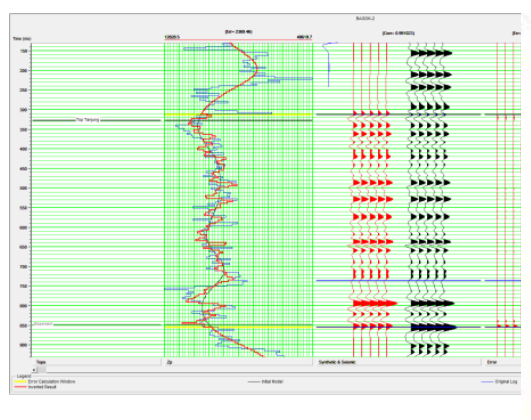

Gambar 3.5 Hasil analisis Inversi Model Based pada sumur B-2

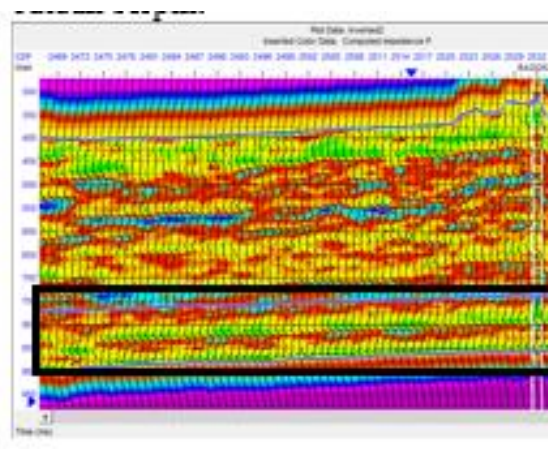

Gambar 3.6 Hasil inversi Impedansi Akustik pada lintasan 91 tr-46 yang melewati sumur B-2

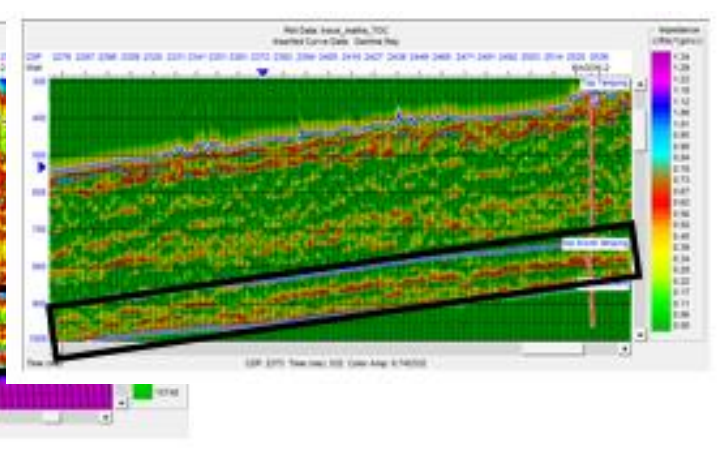

Gambar 3.7 Hasil inversi Impedansi Akustik pada lintasan 91 tr-46 yang melewati sumur B-2

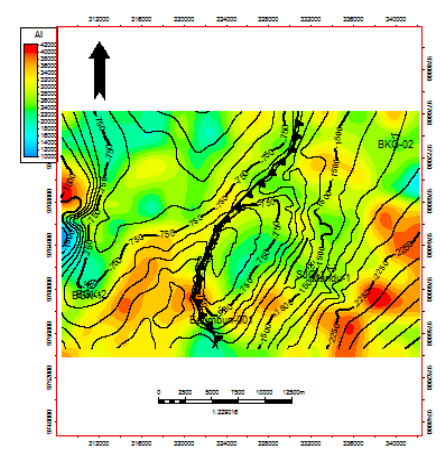

Gambar 3.8 penyebaran Inversi Impedansi Akustik pada formasi Top Lower Tanjung

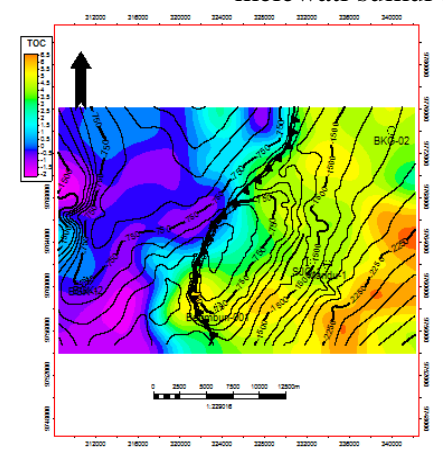

Gambar 3.9 Peta penyebaran TOC pada daerah penelitian

\section{SIMPULAN}

Berdasarkan hasil pengolahan data dan analisis pada Formasi Tanjung, Cekungan Barito, Kalimantan Selatan, terdapat beberapa kesimpulan, yaitu :

1. Karakteristik Geokimia Serpih memiliki tingkat kandungan material organik dengan klasifikasi tinggi berkisar 1.26 - 5.98 wt\% (Baik - sangat baik). Berdasarkan analisis pirolisis kandungan material organik adalah kerogen Tipe II dan III sehingga menghasilkan oil - gas. Berdasarkan tingkat 
kematangan material organik dengan nilai reflektansi vitrinit antara $0.52-0.63$ dengan awal jendela kematangan pada kedalaman 2170 meter (early mature).

2. Analisis perhitungan TOC kontinyu di Formasi Tanjung menggunakan metode multi linier regresi didapatkan korelasi sebesar 0.924, sehingga perhitungan TOC kontinyu pada Formasi Tanjung sesuai menggunakan metode multi linier regresi.

3. Analisis inversi impedansi akustik menggunakan model based dapat terlihat bahwa batuan serpih potensi gas serpih memiliki nilai impedansi berkisar antara $17718-28222 \mathrm{ft} / \mathrm{s} * \mathrm{~g} / \mathrm{cc}$

4. Arah penyebaran batuan serpih sebagai potensi shale hydrocarbon adalah ke arah tenggara daerah penelitian sekitar sumur M-1, S-1 dan Brb-1, pada kedalaman diatas 2100 meter, dengan ketebalan diatas 50 meter.

\section{DAFTAR ACUAN}

[1] Jarvie, D.M., Hill, R.J., Ruble, T.E., dan Pollastro, R.M., (2007). Unconventional shale-gas systems: The Missisippian Barnett Shale of north-central Texas as one model for thermogenic shale-gas assessment. AAPG Bulletin, 91, 475-499.

[2] Perbawa, A., Kusuma, B., \& Winardhi, S. (2012). Integration of Seismic Inversion, Pore Pressure Prediction, and TOC Prediction in Preliminary Study of Shale Gas Exploration. 37th HAGI Annual Convention \& Exhibition.

[3] PERTAMINA. (2013). Laporan Akhir Studi dan Evaluasi Regional Geologi-Geofisika untuk Potensi Minyak dan Gas Bumi Non-Konvensional (Shale Gas, Shale Oil, dan Tight Sand Gas) di Kalimantan dan Kawasan Timur Indonesia. Pertamina, Jakarta.

[4] Peters, K.E., dan Cassa, M.R., 1994. Applied Source Rock Geochemistry, Dalam The Petroleum System-from source to trap, ed., Magoon, L.B., dan W.G. Dow, AAPG Memoir 60, 93-120.

[5] Russel, B. (1996). Introduction to Seismic Inversion Method, S.N. USA: Domenico Sereis Editor Course Notes Series Volume 2 An SEG Continuing Education Short Course.

[6] Sukmono, S. (2007). Post and Pre Stack Seismic Inversion for Hydrocarbon Reservoir Characterization. Bandung: Labolatorium Geofisika Reservoar, Program Studi Teknik Geofisika, Institut Teknologi Bandung.

[7] Van Krevelen, D.W., 1961. Coal. Elsevier, New York. In: The Biomarker Guide, Biomarkers and Isotopes in the Environment and Human History Vol.1, Cambridge University Press, 72156

[8] Waples, D.W., 1985. Geochemistry in Petroleum Exploration. International Human Resources Development Corporation, Boston, 232 hal.

[9] Tissot, B.P. and Welte, D.H., 1984. Petroleum Formation and Occurrence 2nd Edition. Published by Springer - Verlag, Berlin-Heidelberg-New York-Tokyo, 699.

[10] Rotinsulu, lindy, Sardjono, Sumuyut, dan Heriayanto, Nandang. 1993. The Hydrocarbon Generation and Trapping Mechanism within The Northern Part of Barito Basin, South Kalimantan. Proceedings Indonesian Petroleum Association: Twenty Second Annual Convention.

[11] Satyana, Awang dan Silitonga, Parada.D.. 1994. Tectonic Reversal in East Barito Basin, South Kalimantan: Consideration of The Types of Inversion Structures and Petroleum System Significance. Proceedings Indonesian Petroleum Association: Twenty Third Annual Convention.

[12] Verma, Sumit., \& Marfurt, Kurt. (2014). A Way of TOC Characterization on Barnett and Woodford Shale. Search and Discovery Article \#80429. University of Oklahoma, Norman, OK. 